\title{
Criatividade na Contemporaneidade: conexões atuais e possibilidades futuras para abordagem educacional em Design de Moda
}

Creativity in Contemporary: current connections and future possibilities for educational approach in Fashion Design

THEIS, Mara Rubia; Mestra; Programa de Mestrado Profissional em Design, Universidade da Região de Joinville (Univille).

marubiat@yahoo.com.br

EVERLING, Marli Teresinha; Doutora; Pontifícia Universidade Católica do Rio de Janeiro (PUC-Rio). marli.everling@gmail.com

\section{Resumo}

Este artigo apresenta a criatividade como potencial inerente ao ser humano a ser incentivado nas estruturas sociais na qual esteja inserido. O campo da educação tem sido considerado o espaço adequado para o desenvolvimento deste potencial com vivências reais de estudantes no contexto que os cerca. O objetivo deste estudo é discutir como a criatividade pode ser explorada em atividades educacionais da área de Moda associadas às ações de extensão. Nesta proposta pretendia-se conectar o aprendizado a partir da integração ensino, pesquisa e extensão por meio da aplicação do design de moda para o desenvolvimento e criação de figurinos de dança personalizados para bailarinos da APAE (Jaraguá do Sul/SC); Além do próprio figurino como resultado, observou-se também a importância do fazer para refletir com as manualidades, a criatividade e a participação coletiva.

Palavras Chave: criatividade; ser humano; educação; design de moda.

\begin{abstract}
This article presents creativity as an inherent potential to the human being inserted in social structures. The education field has been considered a good space for this potential development with real experiences of the students in the context that surrounds them. The aim of this study is to discuss how creativity can be explored in educational activities of the fashion area with community activities. In this project we intended to connect learning, research and extension processes through fashion design for the creation of dance customs for the APAE organization (Jaraguá do Sul/ SC); In addition to the customs, as a result, it was observed how important it is to link crafts, creativity and collective participation.
\end{abstract}

Keywords: creativity; human being; education; fashion design.

\section{Introdução}

O presente artigo discute a importância das habilidades práticas a partir de atividades manuais (artesanais ou analógicas), complementando as atividades teóricas (intelectuais) na aprendizagem dos estudantes de moda e vestuário aplicadas no processo criativo que envolve o 
"criar, desenhar, modelar" e metodologias ativas como o ensino por projeto de forma interdisciplinar.

A reflexão proposta neste artigo $^{1}$ parte de uma revisão bibliográfica com aporte teórico embasado em autores como Gomes (2001), Ostrower (2001), Sanders (2012), Sennet 2009 e Wolff (2009). A análise de práticas utilizadas no processo de ensino e aprendizagem conta com a abordagem de metodologias ativas (Móran; 2015), direcionadas à aprendizagem no design conforme discutido por Everling (2011); as atividades foram realizadas à luz do projeto de extensão para a criação e o desenvolvimento de figurinos de dança personalizados para bailarinos da Associação de Pais e Amigos dos Excepcionais - APAE, considerando conceitos e concepções como: design participativo, design colaborativo e métodos manuais desde a criação e execução incluindo o desenho, registros de pesquisa, modelagem, costura e bordado com técnicas artesanais, materiais provenientes de resíduos, sustentabilidade e conhecimentos teóricos multidisciplinares que envolveram parte do arranjo produtivo, social e cultural local.

\section{Criatividade contemporânea, inflexão e construção da visão comum para o futuro}

A criatividade tem definições variadas e até mesmo por percepções superficiais ou de senso comum sugerem que apenas alguns indivíduos sejam criativos; esta perspectiva, limitadamente, considera que embora aplicável na vida pessoal e profissional, nem todas as pessoas conseguiriam exercê-la.

Segundo Ostrower (2000), Wolff (1982), Gomes (2001) e Florida (2011) quando associada ao campo das artes, a criatividade artística (literatura, música, pintura, escultura, arquitetura, dentre outras) pode ser definida como criação diferenciada de todas as outras e apresenta alto valor agregado. Outra conexão encontrada é com as oficinas de criatividade provenientes do campo da Educação e da Psicologia que visam potencializar o autoconhecimento, diminuir o estresse e exercitar a aceitação do outro, com aplicação de ferramentas e técnicas ligadas criatividade como o desenho, à pintura e à escultura para o desenvolvimento do pensar com o fazer criativo. 0 desenvolvimento criativo alternativo que tange à vida pessoal e às profissões relacionadas ao Design e projeção de produtos e serviços, como o Design de Moda.

Com o objetivo de complementar e compreender associações sobre a criatividade que poderiam ser úteis ao campo da Moda, foram levantadas informações por meio de brainstorming e entrevistas com educadores da área de Moda (figura 1), acompanhados de consultas bibliográficas para compreender a raiz dos significados das palavras.

1 Este documento foi redigido ao longo da dissertação Criar, desenhar e modelar: o desenvolvimento de conteúdo interativo para aprendizagem nos processos de design de moda (THEIS, 2018) e algumas informações se converteram em fundamentos e argumentos da mesma. 
Figura 1 - Registro de atividade de entrevista com educadores

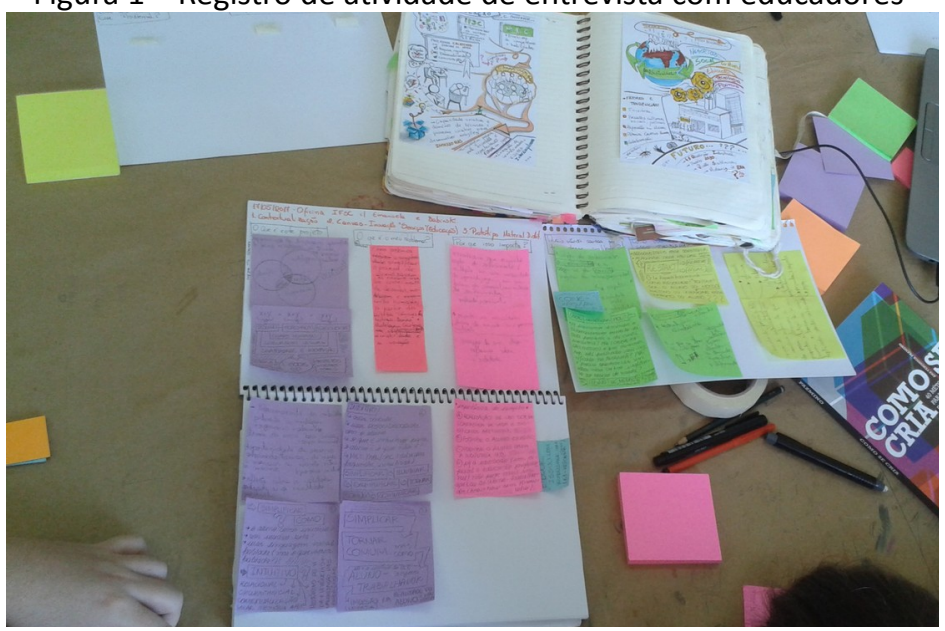

Fonte: primária (2016)

A preparação, desenvolvimento, análises e sínteses das atividades junto aos educadores e grupo de pesquisa tem considerado os conceitos do design participativo, educação colaborativa e ferramentas que valorizam estímulos de produção visual e colaborativa, com registros em mapas mentais (figura 2) e sketchbook².

Figura 2 - Mapa mental sobre criatividade

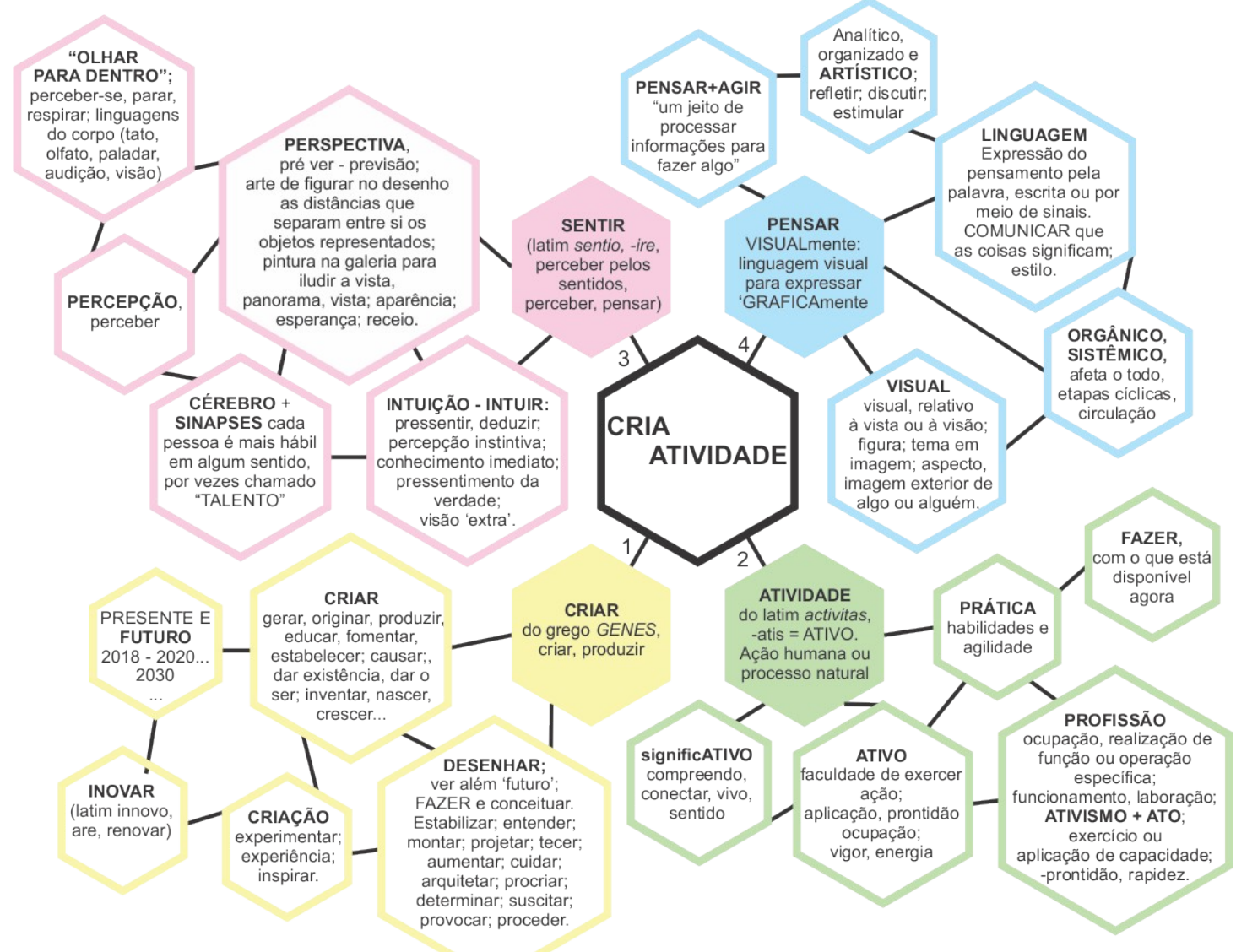

Fonte: primária (2016)

Os resultados obtidos foram organizados por agrupamento de palavras derivadas; também

2 Sketchbook: é um caderno de esboços, que pode ter linhas ou não, constituído por papéis de diferentes gramaturas (e outros materiais) no qual é possível registrar ideias, sínteses de pesquisas e construir composições para posteriormente transformar em informações para atividades de criação dos projetos. 
foram investigados seus significados auxiliando na compreensão do pensamento visual; os termos foram dispostas em um mapa mental apresentado na figura 2. As informações foram agrupadas em quatro grupos com associação de significados: (1) criar; (2) atividades, fazer; (3) sentir; (4) pensar (visualmente). A leitura do mapa mental sobre criatividade materializa a interconexão entre o viver (ação) e o criar, um sentido global.

A figura 2 revela significados e associações relacionados à criatividade como essência e potencial criador de cada ser humano, uma característica orgânica e sistêmica com intensa conexão entre o cérebro, as emoções e o fazer humano, bem como, sua interação e comunicação interpessoal. O olhar para dentro de si, perceber-se enquanto indivíduo gera reflexão sobre escolhas e consequências, pois o compartilhamento através das relacionamentos sociais afetará a qualidade de vida de todos, abrangendo o ecossistema.

As mudanças causadas no século XX apresentaram desafios exponenciais com a pujança de bens e serviços inclusive na área de moda; a criatividade e a inovação foram conectadas e usadas na projeção de objetos e artefatos, estratégias para o consumismo e geração de lucros. Gomes (2001) caracteriza criatividade como "expressiva e produtiva", podendo ser apresentada por meio da ilusão, invenção e da inovação, em especial quando aplicada como ferramenta projetual para desenvolver objetos.

A criatividade tem potencial construtivo ou destrutivo, dependendo de sua aplicabilidade, e, o século XXI tem sido aclamado, com a era da economia criativa e do conhecimento ${ }^{3}$, em um cenário que requer soluções para os desafios globais.

Segundo Ostrower (2001), a criatividade é inerente ao ser humano; criar faz com que ele compreenda a vida, que tenha percepção de si mesmo, e de que a criatividade é uma distinção humana. A criatividade pode ser expressa como vigor ou energia orgânica generativa da essência humana, integrada ao sentir (intuição), com características sensoriais e sinestésicas que podem ser estimuladas de dentro para fora pela motivação pessoal; ao mesmo tempo é potencializada quando ideias são compartilhadas e que ocorrem em interação com os outros.

Em sua origem, a ideia provém do pensar visual (com o exercício da imaginação), materializa-se em linguagem oral, escrita ou por sinais (desenho) para aprimorar, no fazer, as atividades físicas, motoras contribuindo para o desenvolvimento de habilidades práticas que resultam em inovar ou produzir alguma coisa. "Criar é tão difícil ou tão fácil como viver. E é do mesmo modo necessário" (OSTROWER 2001, p. 166), pois à criatividade faz parte de cada pessoa que é única, dependendo da estrutura social na qual está inserida, suas necessidades individuais associadas ao viver.

A comunicação com o outro, o sentimento de pertencimento a uma comunidade e percepção de poder construir o presente (e o futuro) melhor para todos pautado no respeito, empatia e colaboração, são características ressaltadas nas pesquisas de Liz Sanders ${ }^{4}$ (2012); a autora discute a criatividade como competência a ser colocada em prática; em sua abordagem, propõe a atuação do designer como facilitador da criatividade do outro, sendo esta "a competência mais essencial das pessoas", que pode ser explorada em três níveis: individual, coletivo e multidisciplinar (figura 3) gerando, entre outros resultados, uma consciência coletiva. A autora apresenta a criatividade individual com três camadas (do centro para fora) a cabeça, o

3 Richard Florida (2002, p.44 apud MIGUEZ, 2007, p.105) defende que em economias avançadas hoje estão fundamentadas em economias criativas e um contexto de economias orientadas pelo conhecimento.

4 Elizabeth Sanders (psicologia e antropologia), a vinte e cinco anos é pesquisadora sobre criatividade e o design participativo centrado no humano e formas coletivas de criatividade para interação do humano no contexto ambiental, social e cultural, para uso aplicado na solução de desafios do cotidiano atual e futuro. Parte do princípio que todas as pessoas são criativas independentemente da sua área profissional ou experiência pessoal. Fundadora da empresa "MakeTools" presta serviços de consultoria e educação, produz ferramentas para estimular a co-criação e o design centrado no humano. Disponível em: www.maketools.com. 
coração e corpo; é influenciada pelas interações com o meio ambiente (retângulo), lugares e espaços, adereços e materiais disponíveis para uso. Estas três camadas, expressam o campo da cognição como a "ideia básica" na mente, que passa pelo coração, onde recebe estímulos da emoção e impacta o corpo em uma experiência física e motora materializada nas atividades e no movimento. Assim, são criadas condições favoráveis à criatividade, e, o indivíduo influencia e é influenciado pelos estímulos encontrados no espaço (lugar e materiais) e possibilitará a associação ou bissociações entre ideias desconexas que possibilitam o ato criativo para as artes, ciências e outros campos, como a moda por exemplo.

Figura 3 - Criatividade, competência individual e coletiva

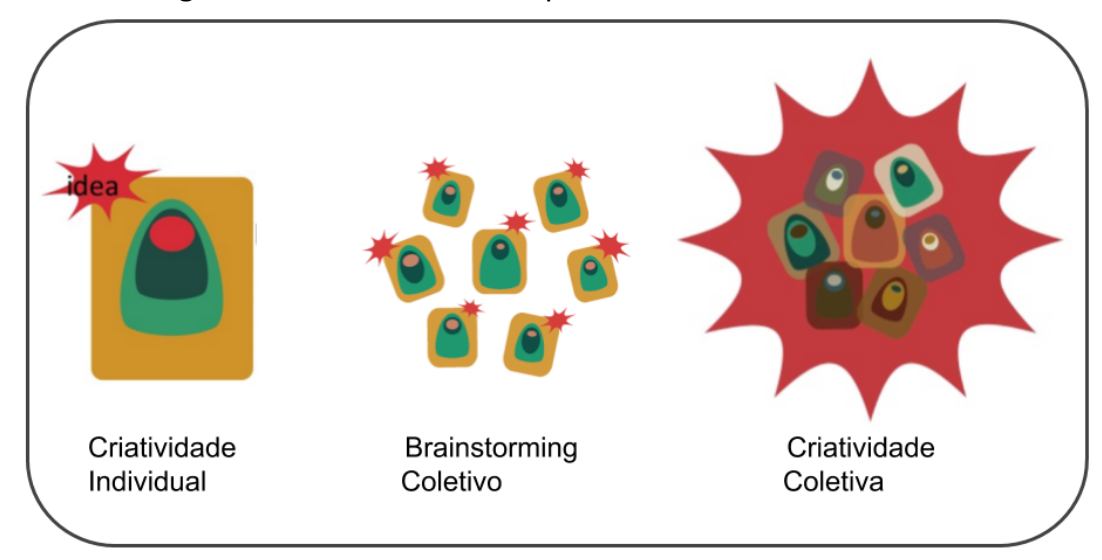

Fonte: adaptado pelas autoras, Sanders (2012)

Para Sanders (2012) a criatividade ocorre com a inseparável conexão entre a cognição e a emoção (mente e coração) que se estende ao corpo em movimento no espaço facilitando as interações de duas ou mais pessoas em atividades como o braisntorming coletivo oportunizando a conexão de ideias diferentes e troca de experiências, em um processo individual que pode levar tempo e etapas como: preparação, incubação, interiorização, iluminação e verificação (GOMES, 2001). A criatividade coletiva reunirá pessoas no contexto pleno "coração, corpo, espaço, ferramentas e materiais" e expandirá esse espaço com a interação de pessoas, fluxos de ideias e pensamentos em prol de uma ação comum, trabalhando juntas com liberdade, autonomia, empatia e colaboração com troca de experiências e "a soma das habilidades criativas individuais sendo exponencialmente maior que o todo". Sanders ressalta a importância de desenvolver espaços que possibilitem a participação sócio-prática, para que as pessoas possam contribuir na solução de desafios ao combinar diferentes perspectivas e gerar novos entendimentos. Para isso, paredes, painéis, papéis e canetas são parte das estratégias para orientar o objetivo e analisar com cautela os riscos e benefícios da criação de soluções; a autora culmina seus estudos em caixas de ferramentas personalizadas (make tools), para potencializar a criatividade pensando cada situação e espaço/tempo, no "fazer com/em processo" (to make) o outro, e não apenas o "fazer sem reflexão" (to do)".

A reflexão deve ser premissa do trabalho criativo; segundo Wolff ${ }^{5}$ qualquer profissão tem caráter livre ao discutir sobre a criatividade artística e sua interdependência com as estruturas sociais. $\mathrm{O}$ artista identificado em sua individualidade, é um potencial agente social transformador inserido na sociedade; ao acessar técnicas existentes, interage com as estruturas sociais e estimula o fluir da ação criativa e inovadora.

"Fazer é pensar" afirma Sennett (2009); é gerar a energia vital para agir e reagir nas intempéries da vida, desenvolver "relações íntimas entre a mão e a cabeça". O conhecimento gerado pelas mãos hábeis, no toque e com movimento evoluem para a imaginação, linguagem que comunica e orienta a habilidade corporal que mostra como fazer, como utilizar uma ferramenta e 5 WOLFF, 1982. 
proporcionar experiências instrucionais que resultam na qualidade de fazer melhor as coisas. $A$ ideia dialoga com trabalho e a prática material do ser humano que se reinventa nas habilidades e nas técnicas; gera reflexão para além do "como" fazer, orientado para o "por quê" fazer, com equilíbrio entre o pensamento e o sentimento de prazer contidos no processo de fazer.

Envolver as pessoas nos projetos desde o início da abordagem do problema é sinônimo de qualidade nos resultados; para Sennett (2009) gera motivação: "o ethos do artífice é o desejo de fazer benfeito" ao exercer habilidades para conhecer e aprender com situações em novos territórios, identificar e solucionar problemas. A organização do processo como um "ritual" que prepara o espaço, as ferramentas e organiza os pensamentos e materiais, exige organização do pensamento e disciplina para o corpo, o amor pelo trabalho com qualidade de vida para todos.

Para Carvalhal (2014) o processo de observação pessoal do mundo exterior e interior, estimula a criatividade, oportunizando identificar o propósito maior que há na atuação profissional e do individual para coletivo, explorando processos colaborativos. Sendo que, "a moda imita a vida", há de se desenvolver uma nova maneira de pensar e de ser; aceitar que o mundo mudou sim e o "nosso" comportamento em relação a ele deve mudar.

Ao acompanhar a sinergia desse diálogo híbrido, proveniente de campos multidisciplinares (antropologia, psicologia, sociologia, administração, educação, artes, design, moda) é possível perceber que há conexão dos conceitos relacionados a criatividade. O desafio prossegue em resgatar a consciência pessoal e social do desenvolvimento do potencial criativo dos seres humanos, motivados a fazer com qualidade e excelência a favor da vida, com nitidez sobre a complexidade do aprender a aprender, ensinar e aprender, viver e conviver socialmente (MÓRAN apud EVERLING, 2011) princípios estes que são base da educação colaborativa ${ }^{6}$, essencial para os estudantes e instituições educacionais do século XXI.

\subsection{Educação contemporânea e o Design de Moda}

O percurso educacional propicia ao indivíduo vivenciar a socialização, internalizar as normas sociais e valores culturais de forma sistemática e organizada. É um projeto a longo prazo (para a vida) que deve zelar pela credibilidade acadêmica, examinar e alinhar as possibilidades ao esboço dessa nova trajetória a ser explorada. O sistema educacional, de acordo com Móran (2015) precisa ser repensado como espaço estratégico, inovador e flexível que permita a jornada de reflexão e ressignificação individual e coletiva, de pessoas e profissionais a serem "preparados para este mundo, capazes de enfrentar escolhas complexas, situações diferentes, capazes de empreender, criar e conviver em cenários em rápida transformação". A urgência de identificar problemas e projetar soluções (artífice/design) por vezes não permite testar as soluções e avaliações sobre os riscos e benefícios equilibrados nos resultados.

A escola deve ser este espaço que permita o aprendizado com exercício para aplicação prática real. Diante da proposta desta nova trajetória, o professor pode fazer uso de metodologias ativas $^{7}$ visando o processo do aprendizado mais significativo junto ao caminho a ser percorrido

6 Educação colaborativa é apoiada em 4 pilares da Educação para o Século XXI, assunto abordado pelo coordenador Jacques Delors no relatório para UNESCO, também em formato de de livro: DELORS,Jacques (org.). Educação um tesouro a descobrir - Relatório para a Unesco da Comissão Internacional sobre Educação para o Século XXI. Editora Cortez, 7̣ edição, 2012.

7 Metodologias ativas: "como o ensino por projetos de forma mais interdisciplinar, o ensino híbrido ou blended e a sala de aula invertida. Outras instituições propõem modelos mais inovadores, disruptivos, sem disciplinas, que redesenham o projeto, os espaços físicos, as metodologias, baseadas em atividades, desafios, problemas, jogos e onde cada aluno aprende no seu próprio ritmo e necessidade e também aprende com os outros em grupos e projetos, com supervisão de professores orientadores."(MÓRAN, 2015, p 15) 
para alcançar os desafios constituídos para o estudante nos objetivos traçados:

As metodologias precisam acompanhar os objetivos pretendidos. Se queremos que os alunos sejam proativos, precisamos adotar metodologias em que os alunos se envolvam em atividades cada vez mais complexas, em que tenham que tomar decisões e avaliar os resultados, com apoio de materiais relevantes. Se queremos que sejam criativos, eles precisam experimentar inúmeras novas possibilidades de mostrar sua iniciativa. (Móran, 2015, p. 15)

A metodologia ativa somada às tecnologias de comunicação torna a sala de aula em janela expandida para o mundo, laboratório que propicia compartilhamento, colaboração e execução dos projetos e oportuniza apropriação dos conhecimentos. A problematização estimula pesquisas, a interdisciplinaridade e aplicação prática em situações reais (do ponto de vista intelectual e vivencial) assimiladas a realidade humana e social, compreendendo ser possível interferir. Essa nova configuração de sala de aula, permitirá ao estudante a personalização do aprendizado a partir de reflexões críticas e processos práticos e ao professor nova atuação junto à construção aprendizagem.

\footnotetext{
O papel ativo do professor como design de caminhos, de atividades individuais e de grupo é decisivo e o faz de forma diferente. O professor se torna cada vez mais um gestor e orientador de caminhos coletivos e individuais, previsíveis e imprevisíveis, em uma construção mais aberta, criativa e empreendedora. (MÓRAN, 2015, p 27)
}

A conexão entre o mundo físico e o mundo virtual requer novas propostas pedagógicas para os estudantes do século XXI; as tecnologias são parte essencial para sua vida, estimulando os estudantes a "aprender a conhecer" e permitindo a formação de profissionais mais criativos, competentes, críticos e autônomos, hábeis em administrar conflitos, com visão holística proveniente do pensar coletivo e a interdependência de todos para obter sucesso, sem luta e competitividade.

No campo do Design, Everling ${ }^{8}$ (2011) destaca a importância de observar essas características do contexto atual para planejar espaços de aprendizagem educacional abertos e apoiados no ambiente virtual. Discorre sobre várias abordagens teóricas no campo educacional como aprendizagem colaborativa, mediação pedagógica, aprendizagem significativa (dentre outras) aplicáveis no ensino do Design que, em processos criativos de design fazem uso de metodologias ativas como o projeto que requer conhecimentos interdisciplinares.

A revisão bibliográfica, até aqui conduzida, esboça conceitos aplicáveis ao aprimoramento do processo educacional (ensino e aprendizagem) em cursos de Design de Moda e Vestuário, com abordagens colaborativas e participativas, metodologias ativas para estímulo do potencial criativo individual e coletivo desses profissionais.

Ao refletir sobre a aplicabilidade e aprimoramento destes conceitos para o desenvolvimento da criatividade no Design de Moda e Vestuário na realidade do IFSC no câmpus Jaraguá do Sul (junto aos projetos e pesquisas na aprendizagem e no ensino) foi adotada a representação visual das atividades de mapa mental (figura 4), guiadas por três perguntas: por quê?, o quê ? e como? 


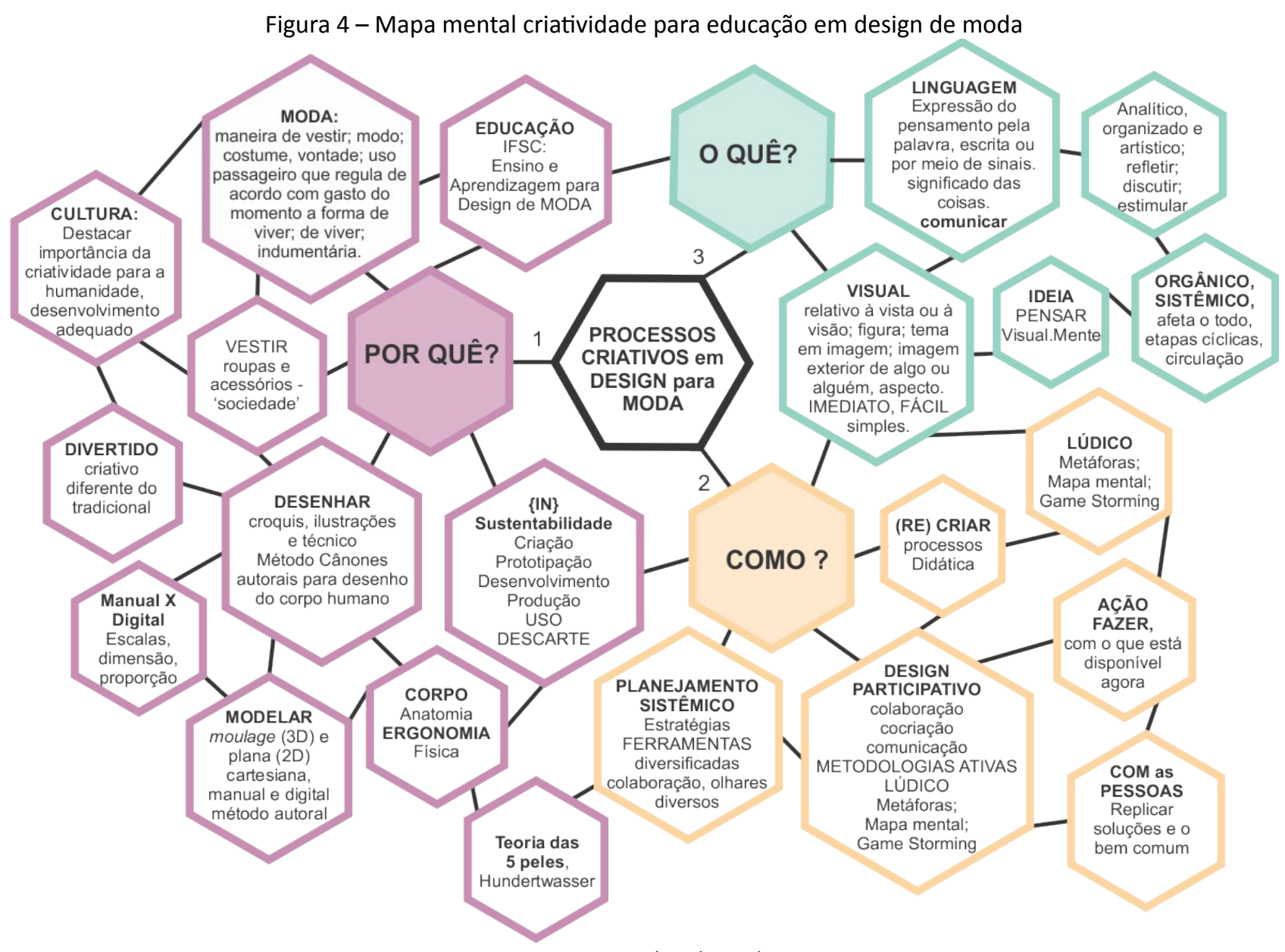

Fonte: primária (2016)

A moda está diretamente ligada à cultura e aos valores sociais, é uma das principais engrenagens da economia, geradora de empregos, de poluição e polêmicas em todo o planeta. Este momento de transformação pode ser a oportunidade para estimular o potencial criativo de todos os envolvidos no sistema moda para discutir e rever as formas de projeção e desenvolvimento de produtos de moda e vestuário. O campo da educação pode ser o espaço que oportunize aos estudantes, educadores e sociedade em geral a investigação, descobertas, questionamentos, discussão, compreensão e novas propostas de "como fazer moda", a partir da realidade local.

A educação precisa ser um caminho aberto e flexível que estimule os instintos criativos das pessoas e coloque o ser humano no centro do processo com disposição para fazermos "com" (juntos) as pessoas, no intuito de possibilitar conexões entre o conhecimento teórico e pragmático, aplicado para a vida. O cenário no qual estamos inseridos, repleto de desafios exige capacidade criativa e flexibilidade; o campo da educação contemporânea necessita de uma revisão, para não mais que acompanhar as tendências e capacitar pessoas para alcançarem o mundo do trabalho, mas, para repensar a qualidade educacional como fonte de energia transformadora, possibilitando tempo e espaço para as pessoas iniciarem um caminho de ressignificação e reflexão para encontrar seu propósito, de dentro para fora, do individual para o coletivo, gerando um novo modelo mental mais livre e criativo.

\subsection{Análise de ações práticas do design de moda, design participativo e colaborativo}

Este estudo parte da consciência que todas as pessoas são portadoras do potencial criativo, relacionado ao cognitivo integrado ao emocional, estendido ao corpo e expansivo no espaço e 
tempo; acredita-se que este potencial é estimulado pela estrutura social na qual está inserido além de atividades práticas em uma atmosfera propícia à geração de ideias individuais e coletivas (com liberdade) refletirá na melhor convivência social.

O propósito dessa reflexão é perceber a aplicação do design participativo e colaborativo junto a projetos de design de moda, ainda que aplicados de forma intuitiva; porém, mesmo assim, as experiências foram impactantes e transformadores utilizando processos pautados na empatia, colaboração e compreensão de que todas as pessoas podem contribuir com sua criatividade.

A proposta selecionada para esta discussão é o projeto de extensão "Modelagem adequada de figurinos de dança para pessoas com necessidades específicas", conduzido pelo núcleo de Design de Moda do Instituto Federal de Santa Catarina - IFSC, Câmpus Jaraguá do Sul para o desenvolvimento de vinte e dois figurinos para os bailarinos da Associação de Pais e Amigos dos Excepcionais - APAE, de Jaraguá do Sul, no ano de 2014. Nesta experiência foi possível perceber o quanto o mundo real pode ser cenário de aprendizagem e que o saber pode ser proveniente de ações empíricas quando observamos o percurso da vida, a intuição e percepção que nos levam a evidências úteis para melhorar a qualidade de vida de todos.

Esta ação, além de explorar os conceitos discutidos ao longo do artigo, estabeleceu uma relação dialógica direta entre as instituições, fomentou a inclusão social, e permitiu a ampliação e consolidação do desenvolvimento acadêmico, profissional e pessoal. O público alvo do estudo foi constituído por vinte e dois jovens educandos com necessidades específicas, acompanhados durante toda execução do projeto por uma equipe técnica multidisciplinar da APAE, composta por cinco profissionais: coordenadora do grupo de dança, professores de arte, coreografia, terapeuta e fisioterapeuta.

\subsection{Criação e desenvolvimento de figurinos de dança APAE}

Este processo criativo de design de moda envolveu professores, técnicos e estudantes do IFSC e da APAE de Jaraguá do Sul e comunidade externa, somando aproximadamente cem pessoas envolvidas. O objetivo principal foi desenvolver figurinos ergonomicamente planejados, com modelagem adequada a cada bailarino do grupo de dança da APAE, atendendo as necessidades específicas de cada usuário para apresentação do espetáculo de abertura do festival "Jaraguá em Dança" na edição de 2014. Esses figurinos deveriam proporcionar a eles mais autonomia, segurança, conforto estético e emocional, facilidade de manuseio e usabilidade, atendendo ainda critérios estéticos, identidade, moda, inclusão social e sustentabilidade.

A demanda para criar, desenvolver moldes e confeccionar os figurinos para os bailarinos chegou a núcleo de design de moda com a solicitação que contribuísse com construção da identidade do grupo e ressaltasse a sua alegria de viver. A estratégia adotada foi criar um cronograma de atividades com encontros quinzenais para envolver todos os interessados no projeto desde o processo inicial de pesquisa e definição de temas, sendo a identidade e diversidade as palavras que iniciaram o brainstorming coletivo. Foram desenvolvidas atividades como o desenho e pintura do autorretrato dos bailarinos (figura 4), para a qual eles receberam sua foto em tons de cinza em tamanho A3 e escolheram cores de tintas para desenvolver a sua arte. A partir dessas referências das pinturas e da observação de características físicas, sonhos e comportamento de cada bailarino, foram desenvolvidos desenhos e proposta de combinação de formas e cores para o figurino, com sua participação na interpretação dos croquis, respeitando detalhes e orientações dos temas e música de cada apresentação e grupo. 
Figura 5 - Bailarinos APAE - cocriação, autorretrato

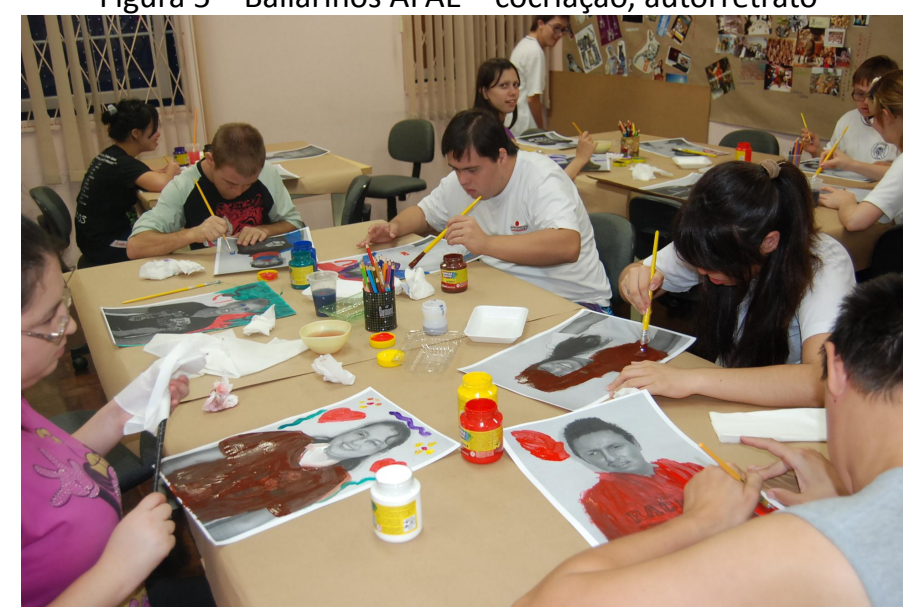

Fonte: arquivo pessoal (2014)

A inspiração para cada grupo de bailarinos teve a influência das músicas que foram escolhidas durante esse processo inicial, da seleção de imagens de temas de moda, e do design e arte que estavam nas tendências de moda do momento; com a contribuição de todos foi construído o painel de inspiração (figura 5); as demais referências foram colocadas no sketcbook que também foi útil para registrar todo o percurso orgânico do projeto.

Figura 6 - Painel de inspiração Identidade e Diversidades APAE

\section{a înspiração}

\section{PAINEL TEMÁ TICO}

Esta coleção teve como ponto de partida as diversas Identidades e Diversidade dos bailarinos

da APAE, cruzada com as referências nacionais como o trabalho de Ronaldo Fraga ao longo de sua carreira e a brasilidade e o colorido do filme "Rio 2 ". A alegria feminina representada na música "Marias" do cantor Ricky Martin. Influências da arte ao mundo da moda através do estilo "artsy" ilustrações, recortes, tendências de moda; silhuetas da década de 20 , a arte surrealista de Salvador Dalí

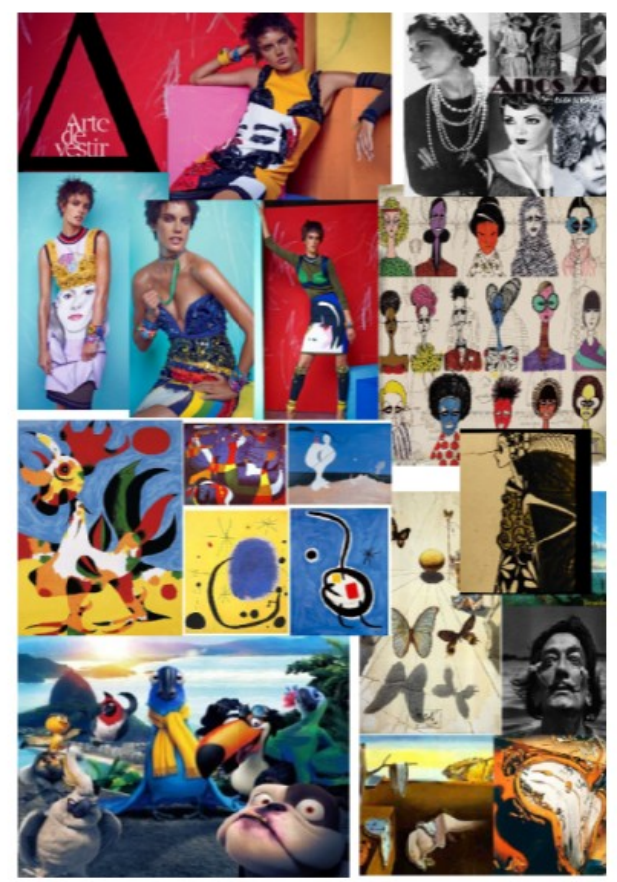

Fonte: arquivo pessoal (2014)

Com a análise dos painéis de inspiração, foram obtidos os elementos do design como formas (geométricas ou orgânicas), cores, texturas, linhas e detalhes para então propor a composição dos looks através dos desenhos de moda (figura 6); também foram selecionadas amostras de tecidos e materiais a serem utilizados na coleção. Todos os materiais utilizados para a construção dos figurinos do grupo de dança foram obtidos pela reutilização de resíduos de confecção, aviamentos, materiais de escola de samba e ateliers de alta costura doados para o projeto, expandindo, assim, possibilidades de composição e seleção de técnicas artesanais para 
aplicação de bordados de patchwork ${ }^{9}$. Cada figurino foi desenhado e apresentado ainda no esboço da proposta de materiais e aviamentos para avaliação e aprovação prévia dos bailarinos, e foi planejado considerando detalhes de seus gestos, comportamentos e sonhos compartilhados durante as sessões de observação e convivência.

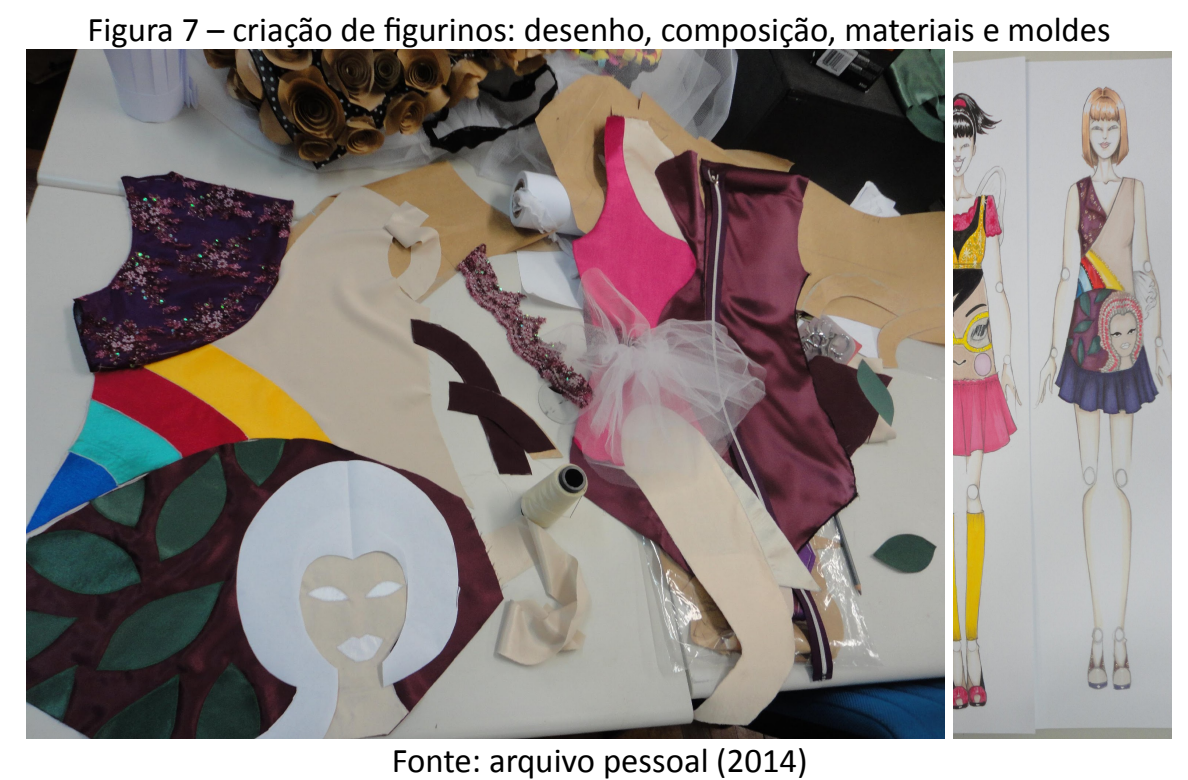

Todos os bailarinos foram analisadas individualmente, com objetivo de oportunizar a eles o desenvolvimento de figurinos de dança que estimulem sua autonomia, bem-estar, melhoria das grandes funções do organismo e melhoria do desempenho de suas apresentações com vestuário que proporcionasse segurança, conforto estético e emocional, facilidade de manuseio e usabilidade. A obtenção das medidas individuais formaram uma tabela de medidas antropométrica para desenvolver o diagrama e modelagem (desenho da estrutura corpórea bidimensional em escala real) dos figurinos com o método de Modelagem Cartesiana para Artigos do Vestuário do IFSC; foi utilizado também o método de moulage (que permitiu desenvolver o modelo diretamente sobre o corpo). As técnicas aplicadas para criar, desenhar e modelar foram analógicas prevalecendo a importância da manualidade aproximando as pessoas envolvidas. $O$ mesmo princípio foi considerado nas representações do desenho de moda, desenho técnico do vestuário, modelagem, adequação ergonômica e costura. A montagem e costura dos protótipos base de figurinos para cada bailarino foi uma etapa essencial para a conferência do caimento e harmonização do conjunto de formas e materiais para cada modalidade.

A prova dos primeiros protótipos dos figurinos (figura 7) foi feita individualmente, visto que cada bailarino tinha características físicas muito distintas; foram também observados a ergonomia física estática e em movimento verificando o conforto e segurança dos bailarinos durante o uso das roupas. Posteriormente foram considerados os ajustes e produzidos os figurinos da apresentação dos bailarinos (figuras 8, 9, 10 e 11). 


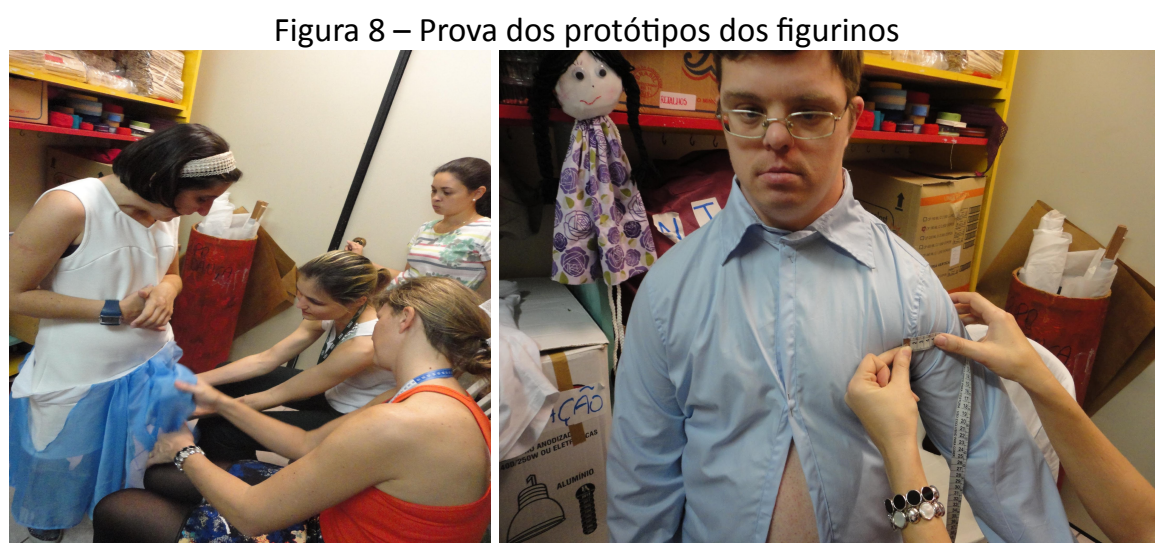

Fonte: arquivo pessoal (2014)

O projeto foi desenvolvido em dez meses de trabalho coletivo; diariamente cada um dos voluntários, a exemplo dos participantes do programa "mãos que ajudam"10 (figura 8), doavam parte de seu dia e contribuíram com suas habilidades em prol da realização dos sonhos de cada um dos bailarinos: vestir seu figurino de dança!

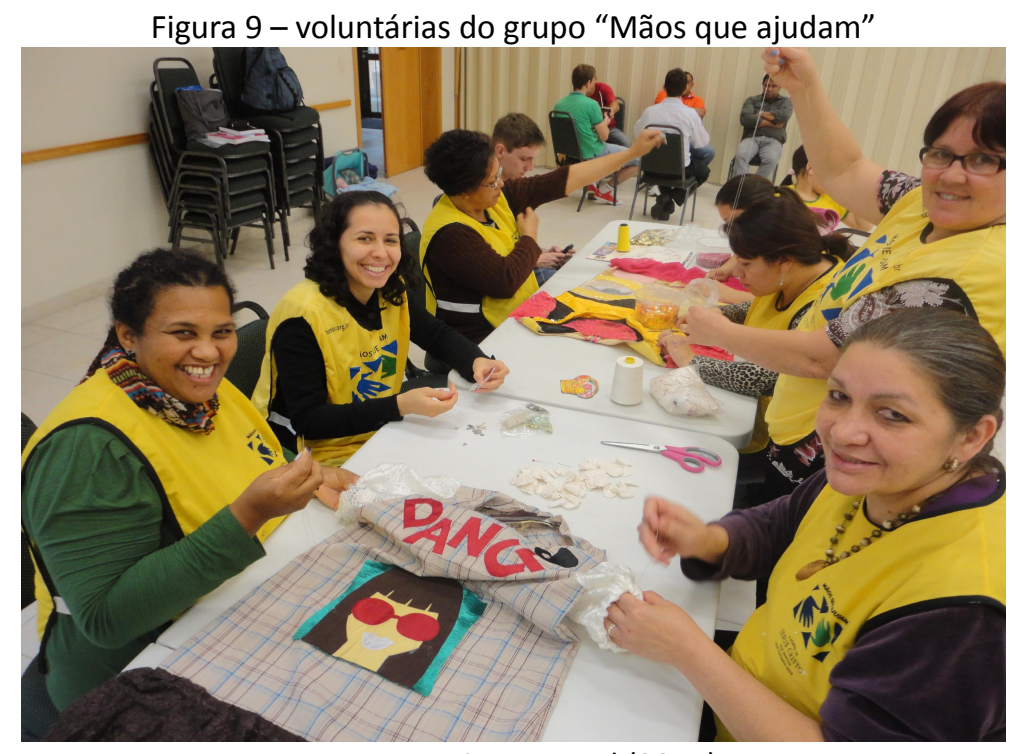

Fonte: arquivo pessoal (2014)

O projeto atendeu critérios associados a usabilidade, experiência do usuário, inclusão, partindo de seu universo, seus sonhos e suas necessidades contribuindo para melhorar a qualidade de vida. Segundo avaliação dos bailarinos e da equipe técnica que os acompanhou; o desenvolvimento dos figurinos individuais, os mesmos proporcionaram conforto estético, psicológico e físico em seu uso para a dança, com respeito de suas limitações, necessidades físicas, intelectuais e gostos pessoais de forma apropriada para as apresentações. Os bailarinos destacaram na avaliação estarem muito realizados, confortáveis e felizes nas apresentações do festival de dança. 
Figura 10 - Bailarinos do grupo misto, identidade "Maria's"

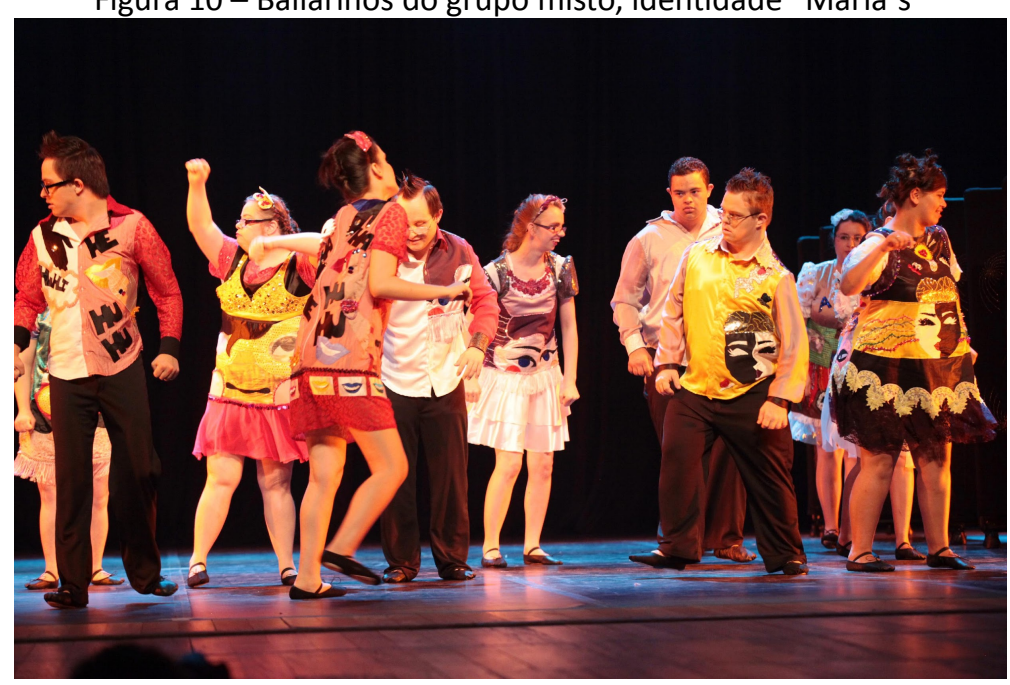

Fonte: arquivo pessoal (2014)

Para a equipe de pesquisa de modelagem e desenho, foi um desafio que consolidou a aplicabilidade de métodos de desenho e de modelagem desenvolvidas na instituição. $A$ equipe interna foi ampliada com a participação ativa da comunidade externa para atender esses bailarinos, contribuindo com olhar e a percepção de quanto a união em prol de um objetivo coletivo pode ser rica; cada um contribuiu com seu melhor da área técnica e profissional, com sua essência humana e amor, em convivência harmônica aprendendo juntos a arte de conviver, uma experiência plena.

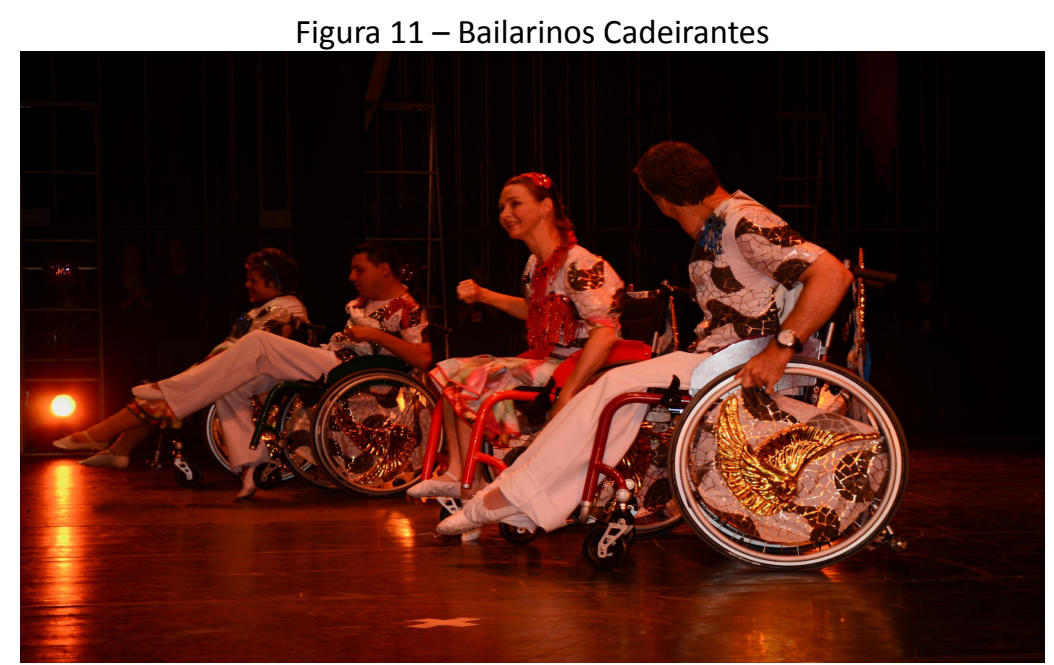

Fonte: arquivo pessoal (2014)

Durante a experiência do processo, percebeu-se que todas as pessoas sempre tem algo a contribuir, ensinar e aprender, ressaltando na prática a importância da empatia, colaboração e do fazer integrado à reflexão.

\section{Considerações finais}

Esta revisão bibliográfica esboça conceitos sobre a criatividade enquanto potencial humano inato, estimulado pela estrutura social na qual esteja inserido, a ser considerado em todas as profissões conectando o pensar, sentir e agir; a reflexão proposta neste artigo é essencial para o aprimoramento do processo educacional de ensino e de aprendizagem para os cursos de Design de 
Moda e Vestuário, considerando abordagens interdisciplinares, colaborativas e participativas.

Diante do complexo contexto social, cultural e econômico no qual estamos inseridos com valores conflitantes, pautados na quantidade e no fazer mecanizado, é possível compreender as dores causadas pela alienação e a deterioração das mentes criativas da humanidade tratadas como máquinas desde a revolução industrial; também é possível compreender como o mundo chegou a essa crise de criatividade, uma crise coletiva que, segundo Sanders (2012), apela por um novo modelo mental compartilhado, empático e criativo estimulando a liberdade, autonomia e equidade, harmonizando a convivência social.

O campo do design de moda faz uso de metodologias ativas (que necessitam ser ampliadas e discutidas), práticas manuais e digitais com objetivo de gerar competências, a partir de conhecimentos e habilidades fundamentais para estimular a criatividade. Esta área do conhecimento valoriza as manualidades que não descartam, mas dialogam com o digital e possibilitam a reflexão (mente) e o desejo das pessoas em fazer bem-feito (manualidades), compreendendo a importância de seu fazer no mundo real e futuro como conscientes agentes transformadores.

As pesquisas na área de criação, desenho e modelagem demonstram aplicabilidade desses métodos e ferramentas que valorizam o fazer e pensar integrados, o desenhar as ideias para a projeção com as pessoas, com a participação ativa e a valorização da experiência do fazer da comunidade na qual as instituições educacionais estão inseridas. No desenvolvimento e construção dos artigos de vestuário gerará possibilidades da compreensão e consciência sobre a importância da sustentabilidade e inclusão de todos, como no projeto dos figurinos de dança, ação extensionista, que enfatizou a importância da tríade ensino, pesquisa e extensão com foco nas pessoas. Nesta experiência, foi possível perceber o quanto o mundo real pode ser de fato uma grande sala de aula, com soluções e ciência proveniente de ações empíricas quando observamos o curso da vida, permitindo a intuição e a percepção guiarem para evidências que proporcionarão melhor qualidade de vida de todos.

E se não for no campo da educação como espaço para repensar, reaprender a aprender, exercitar o fazer coletivo para as soluções de desafios reais, será aonde?

\section{Referências}

ASSOCIAÇÃO BRASILEIRA DA INDÚSTRIA TÊXTIL - ABIT. O poder da moda: cenários, desafios, perspectivas, agenda de competitividade da indústria têxtil e de confecção brasileira, 2015 a 2018. Disponível em: <http://www.abit.org.br/conteudo/links/Poder_moda-cartilhabx.pdf>. Acesso em 22 mai. 2017.

BRUNO, Flávio da Silveira. A quarta revolução industrial do setor têxtil e de confecção: a visão de futuro para 2030. São Paulo: Estação das Letras e Cores, 2016. PDF.

CARVALHAL, André. Moda com propósito: manifesto pela grande virada. São Paulo. Paralela, Estação das Letras e das Cores. 2016

DONDIS, Donis A. Sintaxe da Linguagem Visual. São Paulo: Martins Fontes, 2000

EVERLING, Marli Teresinha; MONT'ALVÃO, Claudia. Diretrizes para um ambiente de aprendizagem assíncrona no curso de design. Rio de Janeiro, 2011. 411p -. Tese de Doutorado - Departamento de Artes e Design, Pontifícia Universidade Católica Rio de Janeiro.

GOMES, Luiz Vidal Negreiros. Criatividade: projeto, desenho, produto. Santa Maria: sCHDs, 2001. 
KORNER, E. ; EVERLING, M. T. . Perspectivas acadêmicas para o ensino do design de moda. In: Elenir Morgenstern e Victor Aguiar. (Org.). Design, Cultura e Sociedade: Limites e Reciprocidades 2. 1ed.Joinvile: Univille, 2016, v. 2, p. 112-131.

MANZINI, Ezio. 2008. Design para a inovação social e sustentabilidade: comunidades criativas, organizações colaborativas e novas redes projetuais. Coordenação de tradução Carla Cipolla. Caderno do Grupo de Altos Estudos, VI. Rio de Janeiro, Programa de Engenharia de Produção da Coppe/UFRJ, vol. I.PDF.

MIGUEZ, Paul. Economia criativa: Uma Discussão Preliminar. In: Teorias e políticas da cultura: visões multidisciplinares. Organização Gisele Marchiori Nussbaumer. Salvador : edufba, 2007 (PP. 95-114)

MÓRAN, J. Mudando a educação com metodologias ativas. In: SOUZA, Carlos Alberto. MORALES, Ofelia Elisa Torres (orgs). Coleção Mídias Contemporâneas. Convergências Midiáticas, Educação e Cidadania: aproximações jovens. Vol. II. Disponível na internet em: < h t t p : / / u e p g f o c a f o t o . word press . co m. Acesso em 10 de maio. 2016

OSTROWER, Fayga. Criatividade e Processos de Criação. Petrópolis, RJ: Editora Vozes, 2001.

SANDERS, Elizabeth B.-N. From user-centered to participatory design approaches. In: FRASCARA, J. (Ed) Design and the social sciences, Taylor \& Francis Books Limited, 2002.

SANDERS, Elizabeth. Creativity in Strategic Thinking. PDF. Disponível em:http://www.maketools.com/articles-papers/Sanders2012Creativity.pdf. Acesso em 28 fev. 2017.

SENNET, Richard. O artífice. Rio de Janeiro, Editora Record, 2009.

THEIS, Mara Rubia; MARDULA, Emanoela; TARACHUCKY, Laryssa. Modelagem Cartesiana e Ergonomia aplicadas na construção de figurinos de dança adequados para pessoas com necessidades específicas, p. 112 - 125. In: Estudos em Design, Revista (online). Rio de Janeiro: v. 23, n. 3, 2015.

THEIS, Mara Rubia. Criar, desenhar e modelar: o desenvolvimento de conteúdo interativo para aprendizagem nos processos de design de moda. 2018. 383 f. Dissertação (Mestrado em Design), orientadora EVERLING, Marli T.; Universidade da Região de Joinville, Joinville.

WOLFF, Janet. A produção social da arte. Rio de Janeiro, Zahard Editores,1982. 